\title{
Raspberry PI for control compact autonomous home farm
}

Ildar Rakhmatulin, PhD

Department of Power Plants Networks and Systems, SUSU

ildar.02010@yandex.ru

\begin{abstract}
This manuscript presented an autonomous home farm for predicting metrological characteristics that can not only automate the process of growing crops but also, due to artificial intelligence, significantly improve the productivity of the farm. The developed farm monitors and manages the next parameters: illumination, soil $\mathrm{PH}$, air temperature, soil temperature, humidity, $\mathrm{CO} 2$ concentration, and soil moisture. Farm can also be used for checking different weather conditions to determine the best temperature value for different crops. This farm as a result is completely autonomous grows tomatoes at home.
\end{abstract}

Keywords: RaspberryPI smart home farm; RaspberryPI for farm control; RaspberryPI for agriculture, RaspberryPI automation, Raspberry Pi \& Internet of Things

\section{Introduction}

Every year the population in the planet grows, but the size of the cultivated area decreases. Colezea, et al. $(1,2018)$ and Heike, et al. $(2,2018)$ predicted food shortages in the following decades. The solutions to this problem are to increase the productivity of the fields using herbicides $(3,2015 ; 4,2008)$ and controlling weeds with higher effectively $(5,2021 ; 6,2020)$. We suggest another way - an autonomous home farm. Today, due to several shortcomings, home farms are not widely used in large cities, since a lot of time must be spent on caring for the crop. But due to neural networks, the farm can not only be automated but also increase its efficiency by creating an ideal microclimate for each crop grown.

\section{Materials and method}

We have created a small home farm - with the ability to control and create a microclimate. Measuring and controlling the next parameters:

- Brightness;

- Soil PH;

- Air temperature;

- Soil temperature;

- Humidity;

- $\mathrm{CO} 2$ concentration;

- Soil moisture.

Ultimately, through machine learning, we taught our farm to automatically adjust the parameters of the devices to create the ideal microclimate. 
The operation algorithm of the device is shown in Fig. 1.

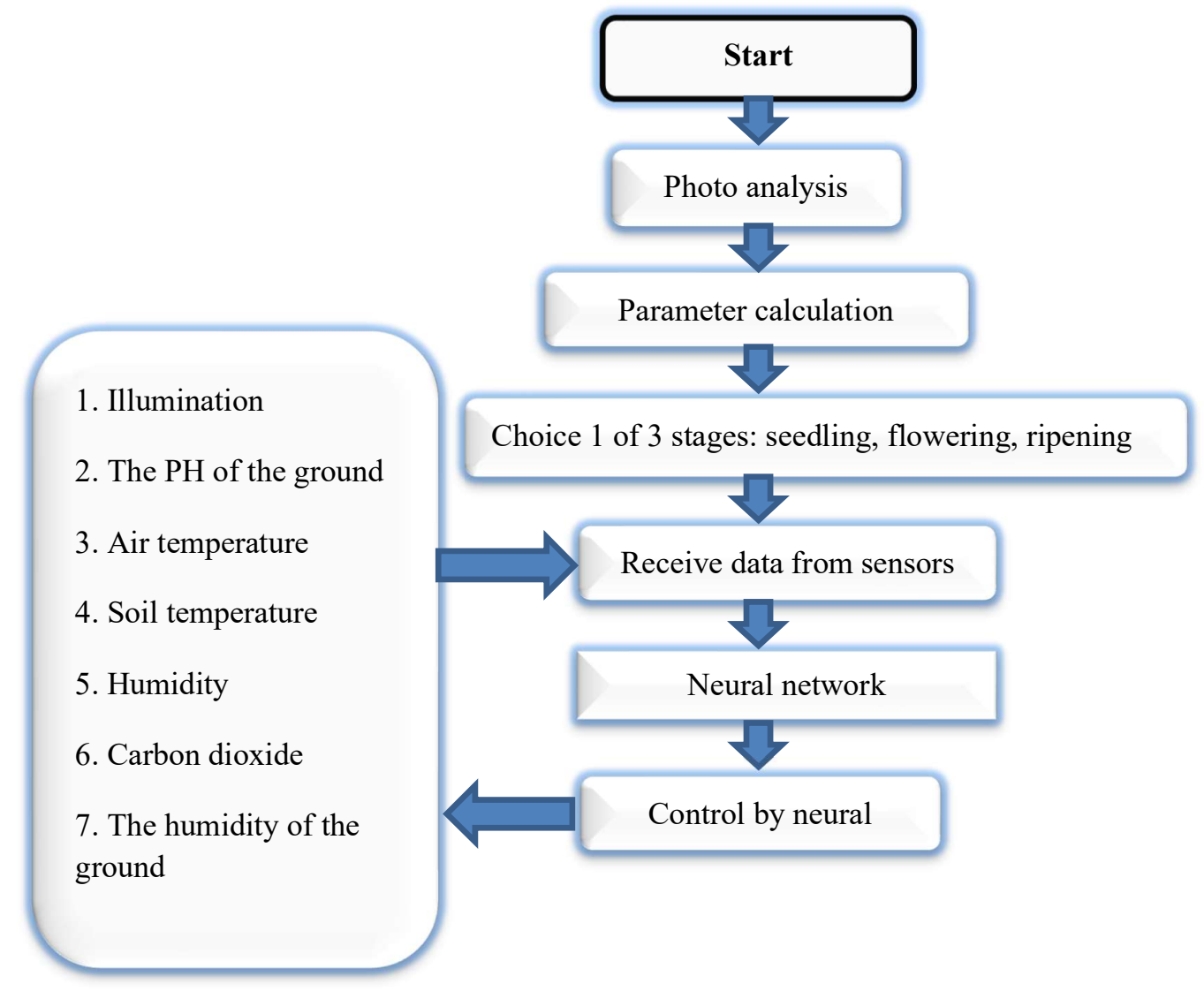

Fig. 1 Algorithm of the home farm

To create a microclimate, we used the following equipment:

- Carbon dioxide - measure with ccs811 (dijital sensor). We can only reduce a value of $\mathrm{CO} 2$ in farm by fan:

- DHT 11 sensor for control humidity and temperature;

- pt100 for control soil temperature. For increase temperature - ceramic heater;

- Analog device for control the soil moisture. For irrigate used a dosing pump.

- Raspberry Pi 3, Broadcom BCM2837B0 (ARM Cortex-A53);

- Software - Python 3.6, OpenCV, PyQt5;

- Picamera, IMX219, Sony;

- Hilitand SM206 digital solar meter to measure the light emission. The brightness of the light is regulated by means of PWM on LED with a wavelength of $620 \mathrm{~nm} \sim 750 \mathrm{~nm}$;

- opt101 to measure brightness.

Figure 2 shows a schematic diagram of the created farm. 


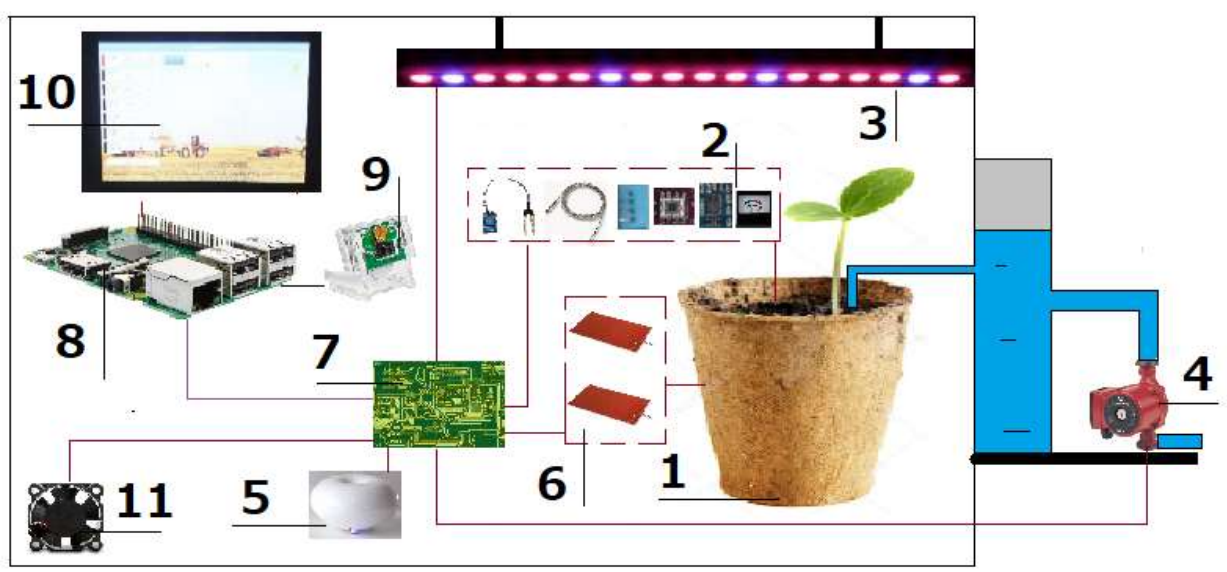

Fig.2. Block diagram of the interaction of sensors and actuators on the farm: 1 - tomato, 2 - box with different type of sensors, 3 - LED, 4 - pump, 5 - water evaporator, 6 - heaters, 7 - converter from analog to digital signal, 8 - RaspberryPI, 9 - Picamera, 10 - graph unit interface, 11- blower

\section{Experience}

We imitated various moments by regulators for creating a different internal microclimate of the farm. Our task was to find the optimal parameters for growing tomatoes. For instance, we lowered the illumination of a grown crop during the germination period to 2700 lux, and then controlled the readings from sensors. Finally, we had a task to redress the disadvantage with different parameters. Finally, we collected the necessary data. Fig. 3 shows the electrical part of the farm.

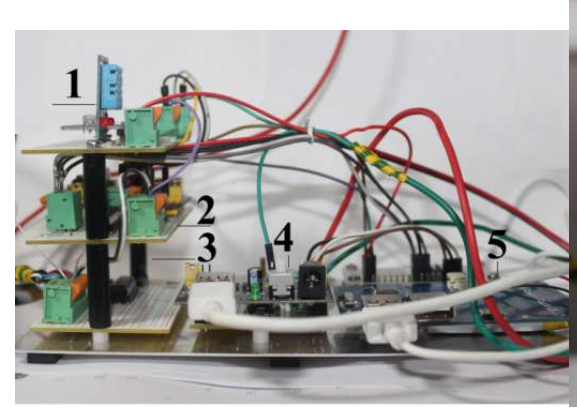

a

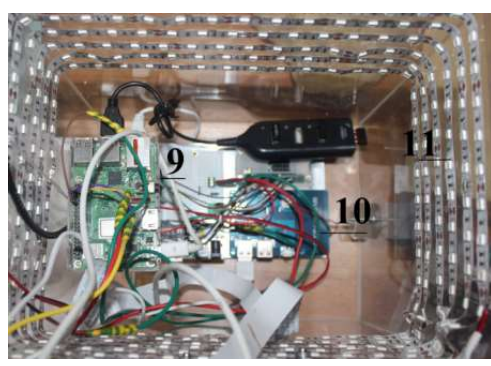

c

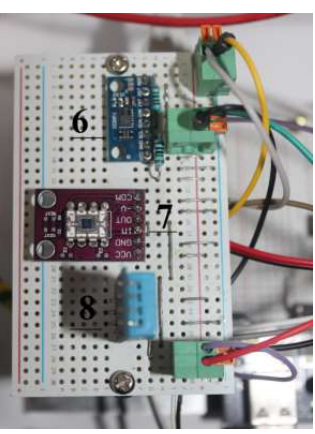

$\mathrm{b}$

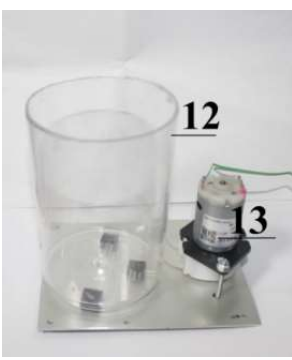

d

Fig. 3. Sensor and actuators: 1 - Side view of the board with sensors, 2,3 - analog boards, 4 - power board, 5 - battery control board, 6 - Carbon monoxide sensor, 7 - brightness sensor, 8 - DHT-11, 9 RaspberryPI3, 11 - lamp, 12 - box for liqued, 13 - electrical pump 
To calculate the date, we can use Raspberry Pi for or data transfer to the cloud and visualization via a web application. We developed software that can help grow a variety of crops. Graphical user interface has different settings and functions for control the conditions of the farm. In the menu is possible to see forecast of ripeness of the harvest, and the state of control actuators. The user interface is controlled on the touch screen, the general view of the interface is shown in Fig. 4.

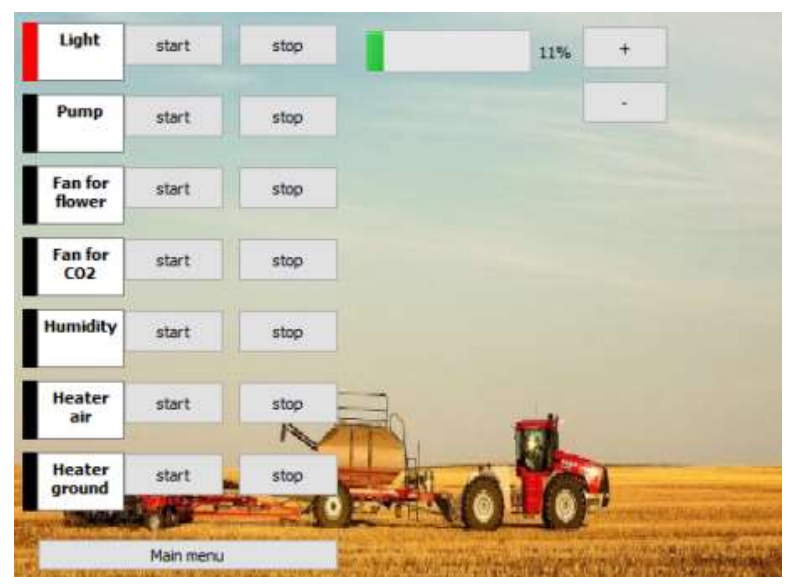

Fig. 4. Appearance of the user interface

The sensor reading is slightly unstable. This is caused by noise in the signal. Of course, this affects the result, but in our case it is insignificant. In this case, the sensors can be replaced with a sensors with lower noise characteristics. General view of the farm, in Fig. 5.

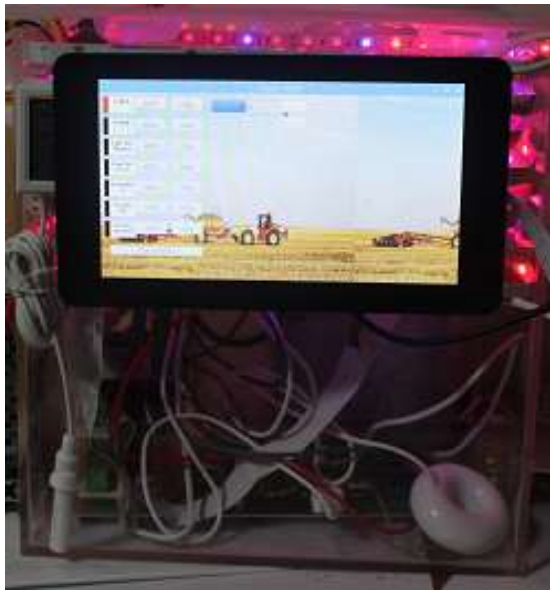

a

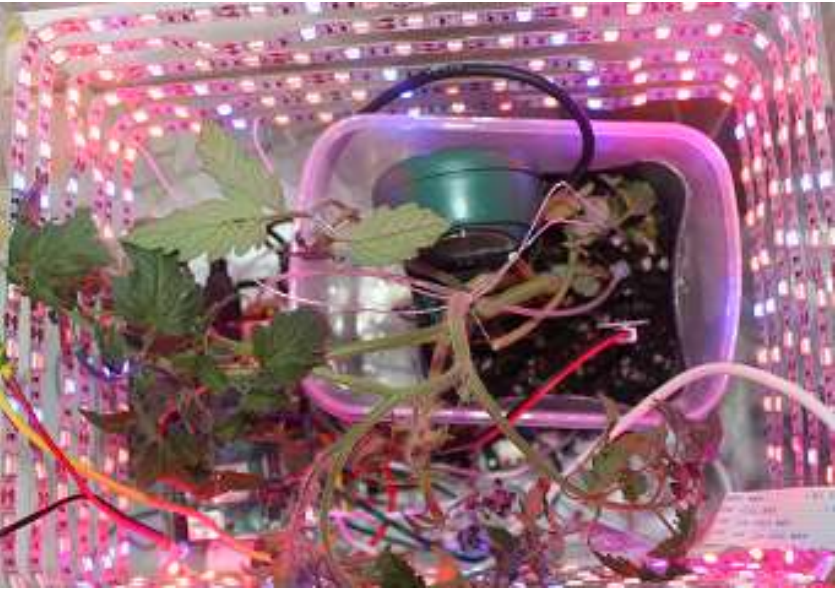

b

Fig.5. General View of the farm: $\mathrm{a}$ - side view, $\mathrm{b}$ - view from above

Increasing the productivity of farms through automation and the use of neural networks has been described in many works. But these works are considered in the context of use in large fields and not in home conditions. Presented farms in these papers have common problems as high price, difficulty in maintenance, and frequent breakdown $(7,2019 ; 8,2011 ; 9,2021)$.

In paper $(10,2021)$, we made an overview of neural networks that were used in agriculture. Based on what we created neural network model. We receive data for the neural network from our sensors in real time. The task of the neural network is to analyze the data from the sensors and then select the optimal settings for the actuators, which should create an optimal microclimate on the farm.

One of the main parameters for a grown crop is temperature. But at the same time, the temperature also affects the accuracy of the sensors. Since the sensors are located in the same microclimate as the grown 
crop. Based on the technical documentation of the sensors we use, their measurement error under normal conditions does not exceed 2 percent. For example, the brightness sensor has a small error over a wide temperature range. But the accuracy of the readings of analog sensors are highly dependent on the ambient temperature. And these changes are not linear. Therefore, it is rather difficult to take them into account. The analog PH sensor reading can change by more than $10 \%$ when the temperature changes within $15 \mathrm{C}$. This can significantly affect the calculations of the neural network.

This problem can be solved by training a neon network. If there is enough datasets, the neural network will be able to find the correlation between the temperature in the ecosystem and the readings of the sensors. In the subsequent work, we will try to find out the required amount of data to teach the network to identify this correlation. But even if this works out, then there will be a problem with replacing the sensors. Since in that case the network will have to be retrained.

\section{Discussion and conclusion}

As a result, we got a fully autonomous low-cost farm with the ability to predict the yield and control executive mechanisms to control the ecosystem of the farm.

In this paper, we did not consider many factors as nitrogen content in soil and leaves, and otherm. We consider only tomato.

\section{References}

1. Colezea, M., Musat, G., Pop, F., \& Negru, C. (2018). CLUeFARM: Integrated web-service platform for smart farms. Computers and Electronics in Agriculture, 154, 134-154

2. Heike, B., \& Bach, M. (2018). Sustainable agriculture and smart farming. Earth Observation Open Science and Innovation, 15, 261-269

3. Vasileiadis, V., et al. (2015). On-farm evaluation of integrated weed management tools for maize production in three different agro-environments in Europe: Agronomic efficacy, herbicide use reduction, and economic sustainability. European Journal of Agronomy, 63, 71-78

4. Gibson, L., et al. (2008). The role and value of eastern star clover in managing herbicide-resistant crop weeds: A whole-farm analysis. Agricultural Systems, 98, Issue 3, 199-207

5. Onasanya, O., et al. (2021).On-farm assessment of cassava root yield response to tillage, plant density, weed control and fertilizer application in southwestern Nigeria. Field Crops Research, 262, 108038

6. Bana, R., et al. (2020). Weed control and rice yield stability studies across diverse tillage and crop establishment systems under on-farm environments. Soil and Tillage Research, 204, 104729

7. Relf-Eckstein, E. (2019). Farming Reimagined: A case study of autonomous farm equipment and creating an innovation opportunity space for broadacre smart farming. NJAS - Wageningen Journal of Life Sciences, 90-91,100307

8. Shaahid, S. (2011). Review of research on autonomous wind farms and solar parks and their feasibility for commercial loads in hot regions. Renewable and Sustainable Energy Reviews, 15, Issue 8, 3877-3887

9. Halgamuge, M. (2021). Internet of Things and autonomous control for vertical cultivation walls towards smart food growing: A review. Urban Forestry \& Urban Greening, 61, 127094

10. Rakhmatulin, I. Artificial Intelligence in Weed Recognition Tasks. AJAST, 4, Issue 2, 70-81, DOI: http://doi.org/10.38177/ajast.2020.4210 